\title{
Editorial
}

\section{A biópsia de medula óssea no estudo das síndromes mielodisplásicas}

\author{
Milton A. Ruiz
}

A introdução da biópsia de medula óssea (BMO) como método de estudo foi descrita no século passado, em 1958, por MacFarland e Dameshek, com o emprego da agulha de Vim Silverman (1). Em 1971, Jamishidi desenvolveu e aperfeiçoou posteriormente a agulha que leva o seu nome. Isto propiciou a obtenção de melhores fragmentos ósseos, que associado ao desenvolvimento de fixadores e de métodos de coloração, contribuiu para o avanço da observação histológica da medula óssea e no diagnóstico das alterações do tecido mielóide com maior amplitude $(2,3)$.

Durante o sétimo Congresso da International Society of Haematology and Blood Transfusion de 1983, realizado em Barcelona, Espanha, Rozman organizou um simpósio satélite no qual o tecido mielóide era valorizado de forma integrada. Nesta nova visão, a medula óssea foi considerada como um órgão complexo constituído de uma parte de estroma - gordura e células - e um arcabouço de suporte constituído de componente ósseo, fibras de reticulina, vasos e nervos, microambiente este, que propicia o hábitat ideal para amadurecimento e posterior liberação dos elementos celulares para o sangue periférico (1).

No Brasil, então, foi descrito nesta época um relato sobre as indicações da biópsia de medula óssea e a obtenção simultânea do aspirado medular, sugerindo o mesmo que o estudo das hemopatias com tal procedimento era mais acurado (4).
Desde a descrição das síndromes mielodisplásicas (SMD) em 1982 pelo grupo Franco-Americano-Britânico, FAB, aboliu-se a terminologia de estado pré-leucêmico (5). Além dos dados clínicos uniformizaram-se os dados citológicos e citoquímicos no sentido de se estratificar as cinco entidades descritas (5). Logo a biópsia de medula óssea veio a ser adicionada nos estudos das síndromes (6). Tricot, em publicações seqüenciais, e com números expressivos de casos, inicialmente em 40 pacientes e posteriormente em mais 70 , descreveu as alterações mais proeminentes desta casuística com SMD (6).

Enfatizou o achado de grupos de células precursoras com localização anormal (ALIP) e conferiu ao dado fator de mau prognóstico na evolução da SMD (6) e que, adicionalmente, a BMO apresentava vantagens em relação aos aspirados medulares (6).

Com a evolução, observou-se que dentre os parâmetros empregados, a citogenética tinha um papel relevante como fator prognóstico, sem que o mesmo reduza a importância da $\mathrm{BMO}$ como método proeminente para o diagnóstico, além de ser um critério obrigatório no estudo inicial destes pacientes. Em que pese ainda existirem muitas imprecisões na análise dos fatores de risco destes pacientes, surgiu em 1997 o sistema internacional de determinação de risco e prognóstico (IPPS) (7). O IPPS enfatiza a importância na análise de risco destes pacientes, o cariotipo, os dados de BMO com o percentual

Coordenador da Unidade de TMO / HB - FUNFARME-FAMERP

Centro Interdepartamental de Transplantes

Correspondência: Av. Brigadeiro Faria Lima, 5416. CEP: 1509-000. São José do Rio Preto. SP

E-mail: milruiz@yahoo.com.br 
de blastos, citopenias e a estratificação dos pacientes em quatro grupos: baixo risco, intermediário 1 ou 2 e de alto risco (7).

Este relato tem o objetivo de ser o preâmbulo para o artigo sobre BMO e SMD que consta deste fascículo de Romeo M. e colaboradores. São descritos e discutidos aspectos histológicos e prognósticos de uma entidade com morbidade elevada, na qual a decisão terapêutica ainda controversa na prática clínica, à luz das novas possibilidades terapêuticas que hoje existem, fazem que o fator idade, performance status do paciente e o IPPS norteiem no momento esta decisão (8).

\section{Referências Bibliográficas}

1. Nieto LH, Rozman C. Biopsia medular en la clínica bematológica, 1980. Salvat Editores SA.

2. Jamishidi K, Swain WR. Bone marrow biopsy with inaltered architecture: a new biopsy device.J Lab Clin Med. 1971. 77: 335.

3. Bartl R, Frish B, Buchenrieder B et al. Multiparameter studies on 650 bone marrow biopsy cores in Frisch B, Bartl R. Bone marrow biopsies updated Bibthca. haemat. Karger. 1984. 1-16.

4. Lorand IGH, Souza CA, Correa JR. Biópsia medular com obtenção simultânea de material para exame citológico (imprint). Seu valor diagnóstico. Bol Soc Bras Hematol Hemot. 1984. 6 (125): 3-7.

5. Bennet JM, Catovsky D, Daniel MT, Flandrin G, Galton DAG, Gralnick HR, Sultan C. Proposals for the classification of the myelodisplastic syndromes. Br J. Haematol. 1982, 51: 189-199.

6. Tricot G, Wolf- Peters C, Vlietink R, Verwilghen RL. The importance of bone marrow biopsy in myelodisplastic disorders in Frisch B, Bartl R. Bone marrow biopsies updated. Bibthca haemat. Karger. 1984, 50: 31- 40 .

7. Greenberg P, Cox C, LeBeau MM et al. International scoring system for evaluating prognosis in myelodisplastic syndromes. Blood. 1997: 2079-2088.

8. Bernasconi C. Evidence based approach to treatment of myelodisplastic syndromes. Haematologica. 2001; 86: 897-899. 